\title{
The cognitive aspect of translation as the reflection of the digital transformation in the modern world
}

\author{
Marina Masalova and Svetlana Shelkovnikova* \\ Don State Technical University, 344000, Rostov-on-Don, Russia
}

\begin{abstract}
The paper aims at considering the peculiarities of the translation process in the period of digital transformation, revealing the trends and identifying the algorithms of the models that facilitate the qualitative translation. The authors state that translation is the process that undergoes the influence of both linguistic and social factors. In the new century the transformation of the translation paradigm can determine the system of qualitative translation content. The digital translation is seen through the cognitive aspect under the conditions of the transformed requirements on the modern period of development. The cognitive model of comprehension, including the text representation and its realization through situational models, background information and individual factors, is determined. The types of comprehension such as semantic, cognitive and extra linguistic are identified as well as their impact on the quality of digital translation. The positive sides of the digital transformation include the widening of the individual communicative opportunities, increasing access to the communicative resources, stimulating the cognitive activity and the translator's work simplification. The authors suggest the algorithm for the development of the specialized computer environment possessing translation skills.
\end{abstract}

\section{Introduction}

The last decades witnessed the growing interest of psychologists, linguists, AI developers and other IT specialists to the problem of comprehension of the natural language, human intelligence functioning, specific features of thinking processes aimed at producing an utterance.

In this connection the study of peculiarities and patterns of translation gain special significance. Translation is the process that undergoes not only linguistic but also social factors. Translation reflects the surrounding world transforming the data of the original language taking into account the determining social factors.

Digital technologies are widely used at present even in training of future translators. The educational process is experiencing a period of transition from traditional synchronous

\footnotetext{
* Corresponding author: vss162@rambler.ru
} 
methods of learning which take place in the classroom to asynchronous ones that can be applied at any place and/ or time and can be presented as distance or e-learning [1].

In our research we mention the fact that translation can be considered as the profitable industry which may function as an independent business structure. Providing a high-quality translation service is one of the factors for the investment potential of the Eurasian Economic Community and a condition for competitiveness in non-resource exports to the foreign markets [2].

The initial point of general theory of translation is the issue of its social nature as the working algorithm and requirements to the quality of the translator's work are determined not by his or her subjective opinion of translation but by definite expectations of the society resulting in certain requirements to the translation [3].

In recent decades, the process of converting the source language into the target language has undergone significant transformations. "The year 2002 is considered the borderline of digitalization: the shares of analog and digital information have become equal. Today, digital era "rules the ball", displacing analog information on the sidelines of the modern development of the information society "[4].

With the emergence of the concept of "digital translation", the translation paradigm is radically changing. At present digital translation belongs to a new type of translation technology, which is a system of network interaction between a specialist and digital information and communication means, contributing to an increase in the efficiency of translation activities and the quality of translation products [5]. There is an essential need to study and analyze the features of digital translation, which we define as the translation of texts from one language into another using specialized computer programs [6].

\section{Materials and methods}

Translation is an important process that can influence various spheres of human activity. The advent of digital translation has changed the system for producing a quality translation product. Digital translation is undoubtedly interesting for representatives of completely different spheres of human activity, linguists, psychologists, IT workers, economists. The striving for fast and high-quality translation determines the trends in the development of the translation sphere in recent years. In this connection, there are many works devoted to various aspects of this problem. These are the works of foreign scholars such as Sh.O'Brien (2015) [7], B.Whyatt (2016) [8] , M.Deckert (2017) [9] and also Russian scholars including T.I. Makarevich. (2020), Latyshev L.K. (2017) , Sadovnichy V.A. (2018) , Garbovsky N.K. (2019) , Gambier I. (2016) [10 ], Savitskaya L.V. (2013) [11], Yakunina V.G. (2017) [12] , Gabdullina A.Sh. (2015) [13], Gavrilenko N.N. (2018) [14]. Due to the theoretical nature of the given paper the descriptive method is mainly used for carrying out the following study and to achieve the needed results.

\section{Results}

Throughout the development of linguistic science, the approach to the concept of cognition has changed. The change in the translation paradigm is determined by the emergence of a new translation technology. The complexity of digitalization of the translation process is that new cognitive approaches in the study of the processing and understanding of natural language, which make it possible to combine linguistic and extra linguistic knowledge, strive to achieve high-quality translation content.

The cognitive model of understanding is determined, including textual representation and realized with the help of situational models, general background information and 
individual factors. The types of understanding, such as semantic, cognitive and extralinguistic, are highlighted, the dependence of the quality of digital translation on them is determined. It is noted that the ultimate goal of translation is not to represent the text, but to add new knowledge to the addressee. Apparently, the undoubted advantages of digitalization are expanding the communication capabilities of the individual, increasing access to communication resources, stimulating cognitive activity and, finally, simplifying the work of translators.

\section{Discussion}

The new paradigm of linguistics highlights language from the perspective of the relationship to the communicative act. It is with this that the language fits into the system of objects that constitute the subject of a comprehensive study of cognitive, linguistic and social factors, which seems to be an urgent scientific problem.

The anthropocentric orientation of the language model in all its globality is actualized by a pragmatic attitude. The basic definitions of the language given by the classics of the past receive a new reading due to the change of emphasis. These new accents also set a number of problems that are solved by modern linguistics: optimization of the "languagemachine" dialogue, "digital translation", the problem of understanding, atomization of the speech act, etc.

The concept of personality in linguistic consciousness is much broader and more indefinite than the corresponding scientific concepts and is reduced to the concept of an individual as a set of properties characteristic of a given person, and a person as a bearer of any properties. Language is most directly related to the expression of a person's personal qualities. At the same time, philosophical, sociological and psychological views on the socially significant combination of physical and spiritual properties of a person, which make up his qualitative determination, are of great importance.

The emergence of "digital translation" defines a characteristic feature of the modern stage of the society's development. Moreover, the question of improving the system of professional training and employment of graduates becomes one of the major problems of modern vocational training educational institutions [15].

Currently, there are several approaches to the problem of comprehension and to the interpretation of knowledge structures in the process of linguistic communication. One approach tends more towards linguistics, the other towards the theory of artificial intelligence. The linguistics of the text determines the emphasis on the greater importance of linguistic processes in the semantics of understanding in comparison with background knowledge, sociocultural context and other extra linguistic factors.

The peculiarity of the approach of the supporters of artificial intelligence to the problems of understanding lies in the fact that the construction of semantic inference as a result of interactions of various types of knowledge does not take into account the specifics of the text. Whereas the solution of a number of tasks, primarily linguistic ones, presupposes a direct relationship between the efficiency of text processing and the degree of consideration of its specifics. The difference between another approach to the semantics of understanding is due to its focus on linguistic processes proper, and the mental substrate on which understanding is based can be presented in terms of propositions, semantic macrostructures, maximally focused on taking into account the specifics of the text.

At the same time, there was an opinion that the complete representation of the text with the active use of context is the ultimate goal of understanding. This has made it possible to advance the solution of many linguistic problems. In particular, the mechanisms of understanding anaphoric and metaphorical expressions, reduced fragments of the text, etc. 
received a different and deeper interpretation. But with the development and improvement of computer technology, everything has changed.

From the standpoint of the cognitive approach, the ultimate goal of understanding is not to represent the text "for the sake of the text itself," but to add new knowledge to the addressee. The same communicative components are present here - the text, the model of the situation, general background knowledge, including the intentions of the addressee and the system of his value orientations, imposed by the professional and socio-political environment, and much more.

The difference is due to the fact that within the framework of a truly cognitive approach, all these components are equal and interrelatedly provide the addressee with new knowledge. If the point of view of the researcher is focused on the dominant role of the representation of the text, then the remaining components are important only to the extent that they are necessary for its implementation. In such a case, the cognitive model of understanding, including textual representation, is realized with the help of the integrative influence of many models of situations and individual factors - age professional, sociocultural, and also taking into account the relevant general background information and the knowledge base of the addressee.

That is, in the process of understanding, we are dealing not only with the processing of the text itself, but also with the socio-political and cultural interpretation of events, as well as with institutional norms. Therefore, only a cognitive approach is currently capable from a unified point of view to integrate various restrictions and types of information in an extremely complex process of language understanding.

Comprehension can be viewed in different philosophical and philological paradigms. In the field of computational linguistics and the study of understanding in artificial intelligence systems, understanding is an increase in information knowledge in the process of communication. In the hermeneutic and analytic traditions, comprehension is the resultant state of interpretation. When understanding the text, the facets of the content of the text itself and the facets of the recipient's experience of the perceiver enter into complex interaction. Comprehension is a properly human activity, since the basis of the entire typology of understanding is the ability to use language as a sign system, which is characteristic only of a human. The problem of comprehension refers to linguistics to the extent that a person's extra-linguistic experience is stored and transmitted in linguistic form.

In the opinion of many modern scholars, the most practical approach is such an approach in which the problems of the text are investigated in connection with the mechanism of its understanding.

Reflection is at the heart of the processes of understanding, since understanding is possible only thanks to the reflexive ability of a person. Therefore, when analyzing the processes of verbal communication and understanding, it is necessary to start from reflection and its cognitive status, as well as its re-expression into understanding.

The following main types of understanding can be distinguished:

- Semantic understanding. Based on verbal memory, it is necessary in various types of speech activity, serves as a basic factor for the comprehension of the text.

- Cognitive understanding. Based on the understanding of concepts and meanings, correlates with real situations and is a prerequisite for the emergence of knowledge.

- Understanding is extralinguistic. Based on the correlation of situations with nonlinguistic factors. See the following figure. 


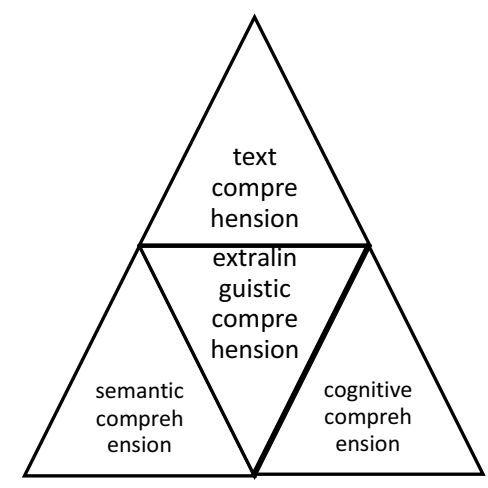

Fig. 1. Main types of understanding

Of all the types of understanding, for a digital translator, extralinguistic understanding seems to be the most difficult due to his lack of mental activity, the ability to compare, as well as personal experience.

Like the computer, information and communication technologies are gradually transforming the translation environment. The translation process and translators, who entered the digital age almost three decades ago, are faced with new challenges and a new social environment that technology has created.

At the same time, the question of how to make a computer translation of the highest quality and equip a digital translator with properties characteristic of a native speaker with translation skills remains open.

At the same time, it is important to note also the speech aspect of mental activity, which is a kind of reverse side of the cognitive aspect, with the general parity of their relations. To clarify the characteristics of each of them in the complex process of speech and mental activity of a person, it is necessary to compare and contrast them according to the same parameters. This is not easy to do, since polar approaches to the relationship between linguistic structures and structures, which can be called cognitive, are well known.

One approach is that language structures are purely formal. They are analogous to formulas and theorems in the theory of logical calculi, which are exhaustively determined by the alphabet, formational and transformational rules and only potentially admit semantisation, not necessarily the only one. Semantization in this case is the establishment of correlations with cognitive structures, which are as independent as linguistic structures, and language acts only as an outer shell of thought,

The opposite approach consists in fact in denying the independence of cognitive structures, since there is a thesis about the lack of structure ("chaos") of thought outside the language, that is, about the illusory nature of independent cognitive structures. Cognitive research cannot remain aloof from translation theory and practice, since one of their tasks is to study the ways of structuring the information flow when transferring the content of the original message into the target language.

The cognitive and speech aspects of thinking, although based on a universal thinking mechanism, undoubtedly differ from each other in goals, results, direction and have a number of other distinctive features.

If we compare cognitive thinking and verbal thinking in terms of the final goal, then the fundamental difference between the two mechanisms that act in this case draws attention: the mechanism of obtaining a new thought and the mechanism of its expression. At the same time, it is obvious that although the expression of thought is a process that, of course, requires mental effort, these efforts are different from those that we spend in obtaining new knowledge. 
With regard to the effectiveness of cognitive and verbal thinking, one can distinguish thought as a result of cognitive thinking, or text as a result of verbal thinking. When we try to explain something, the thought is contained in our mind as a whole, it does not arise gradually by separate units, as our speech unfolds.

Cognitive thinking is an active process of reflecting the objective world, as well as the disclosure of regular connections that exist in reality, the assessment of the result of which is the degree of truth tested in practice. Speech thinking has its own laws and goals, and the successful result is not so much truth as getting an adequate response from the interlocutors, corresponding to the intention of the author of the text.

Thus, cognitive thinking is the knowledge of the objective world, and verbal thinking is the influence on people by linguistic means, since the first is aimed at the objective world, and the second at the interlocutor.

The end result of verbal thinking, therefore, does not depend on the quality of the source material (truth or falsity of cognitive thought) and not on the characteristics of the speaker's thinking, but only on the perception of the text by the recipient.

So, with all the opposition and differences between the cognitive and speech aspects of mental activity, although they are multidirectional, they are still essentially the same speech and thought processes, since they are varieties of a single phenomenon - human thinking, and therefore cannot but have common features .

"The opposition of translation tools to the translation process has led many to overlook how the human translation process has become largely technology-based, especially in commercial translation and product localization."

Modern information technologies are gradually and confidently transforming the computer environment. At the same time, a desire arises to find an algorithm for solving the problem of the most high-quality translation. The question arises of preparing a specialized computer environment with translation skills. In this regard, the following stages of the development of computer models with the ability to translate can be distinguished:

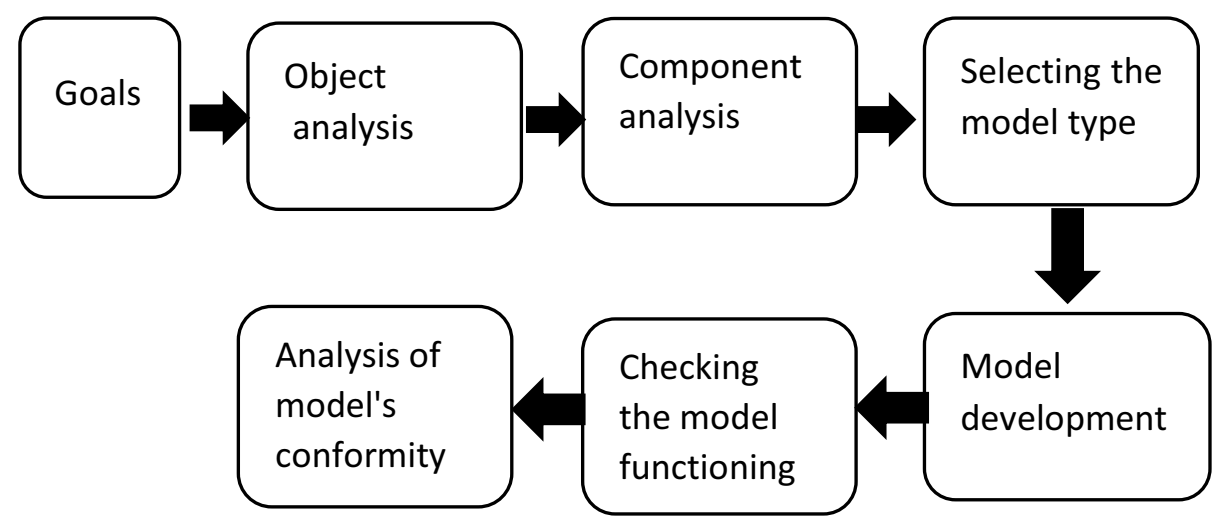

Fig. 2. Stages of the development of computer models with the ability to translate

1. Setting goals for modeling. This is the first stage in the development of the model, which determines all subsequent work. At this stage, the goals of preparing the structure of the translation content are determined, as well as the ways of its functioning in accordance with the purpose of use are checked.

2. Analysis of the simulation object. At this stage, it is necessary to determine the composition of the components of the modeling object. At the same time, the software components of the computer and the information network (processor, RAM, hard disk, network card, sound card, etc.), as well as software are distinguished. 
3. Analysis of the selected components. It is necessary to identify the links between the components, to determine the significant in accordance with the purpose of modeling and inclusion in the structure of the model. Based on the goal, the components that need to be included in the structure of the model to ensure its functioning are determined. At the same time, a choice of software is made that is installed on the model and is able to cope with translation tasks.

4. Choice of the type of the created model. At this stage, the type of software model being developed is determined: a model of a personal computer that is not connected to the information network; model of a personal computer connected to the Internet; local network model.

5. Development of a model using a specialized software environment. At this stage, the environment is selected to support the development of the model. Based on the selected specialized software environment, a translator model is developed.

6. Checking the functioning of the model. At the end of the development of the model, its functioning, the operability of the used software is checked.

7. Analysis of the adequacy of the constructed model to the object and the purpose of modeling. At this stage, the model is verified to reproduce all the characteristics of the modeling object that are essential for modeling purposes.

\section{Conclusion}

Thus, in our work, different approaches to the problem of comprehension and to the interpretation of knowledge structures in the process of communication were analyzed, a study was made of the relationship between linguistic and cognitive structures, as well as the influence of speech and cognitive aspects of thinking on the translation process.

The emergence of a new translation technology has led to a change in the translation paradigm. New cognitive approaches in the study of the processing and understanding of natural language make it possible to combine linguistic and extralinguistic knowledge and at the same time strive to achieve high-quality translation content. This is the complexity of digitalization of the translation process.

The undoubted advantages of digitalization are: expansion of human communication capabilities; increasing access to communication resources; stimulating cognitive activity and, finally, simplifying the work of translators.

The cognitive model of understanding is investigated, including textual representation and realized with the help of situational models, general background information and individual factors. The types of understanding, such as semantic, cognitive and extralinguistic, are highlighted, the dependence of the quality of digital translation on them is determined. It is noted that the ultimate goal of translation is not to represent the text, but to add new knowledge to the addressee.

The change in the features of thought processes aimed at building a speech utterance is established. Digital translation is considered from the point of view of a new paradigm of linguistics - language from the side of attitude to the communicative act. Based on the above, an algorithm for preparing a specialized computer environment with translation skills is presented, the purpose of which is to strive to find ways to establish high-quality translation content.

\section{References}

1. S. Shelkovnikova, E. Krasnova, R. Avedova, 14th International Technology, Education and Development Conference, 9354-9357 (2020) doi:10.21125/inted.2020.2592 
2. T.I. Makarevich, I.I.Makarevich, Vestnik Moskovskogo universiteta im.Vitte 1(2), 86, (2020) https://cyberleninka.ru/article/n/ekonomika-i-upravlenie-na-rynkeperevoda-mezhdunarodnyy-aspekt

3. L.K.Latishev, N.Y.Severova, Vestnik Bryanskogo universiteta 1, 297 (2017)

4. V.A.Sadovnichiy, Matematika v sozvezdii nauk. Izbrannie vistuplenia 197, (2018)

5. N.K.Garbovskiy, Russki yazik i kultura v zerkale perevoda 67, (2019)

6. E.Krasnova, E.Laskina, O.Moisova, E.Velichko, 5th International Multidisciplinary Scientific Conferences on Social Sciences \& Arts, SGEM 5 (3.4), 427-433 (2018)

7. Sh.O'Brien, Interdisciplinary in Translation and Interpreting Process Research 5 (7), (2015)

8. B. Whyatt, Poznan Studies in Contemporary Linguistics 52 (2016)

9. M. Deckert, Research in Language 15(2), (2017)

10. Iv Gambye, Vestnik SPbGU 4, 60 (2016)

11. L.V. Savitskaya, Lingvistika i mezhkulturnaya kommunikatsiya 10, 115 (2013)

12. V.G. Yakunina, Nauka bez granits 6 (11), 18 ( 2017)

13. A.Sh. Gabdullina, Obutchenie i vospitaniye: metodiki i praktika 113-120 (2015) https://cyberleninka.ru/article/n/formirovanie-perevodcheskoy-kompetentsii-ustudentov-v-vuzah-s-ispolzovaniem-sovremennyh-tehnologiy-obucheniya

14. N.N. Gavrilenko, Cross-cultural studies: education and science 3, 415-418 (2018)

15. M.G. Sergeeva, V.Y. Flyagina, I.V. Taranenko, E.V. Krasnova, A.V. Vilkova, Ponte 73(1), (2017) doi: 10.21506/j.ponte.2017.12.30 